\title{
The features of the voice domain: actives, passives, and restructuring
}

\author{
Susi Wurmbrand and Koji Shimamura \\ University of Connecticut
}

\section{Introduction}

Restructuring or clause union phenomena provide an interesting testing ground for the composition of the voice domain. ${ }^{1}$ Restructuring refers to complex predicate constructions in which two lexical domains display mono-clausal behavior as diagnosed, for instance, by the availability of otherwise clause-bound operations such as clitic climbing or scrambling. An illustration is given in (1) from Polish.

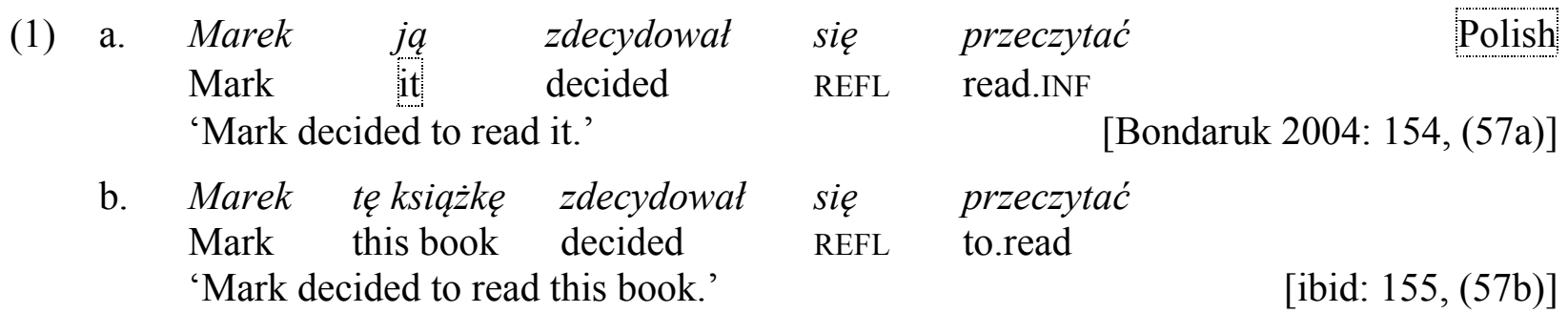

Since restructuring configurations involve a deficient clausal (functional) domain, the properties of these constructions allow us to single out different components of the voice domain. Of special interest for the current paper is the phenomenon of long object movement (LOM) -i.e., constructions in which the object of the embedded predicate is promoted to matrix subject due to passive (or a passive-like operation) of the matrix predicate. As shown in Wurmbrand (2014b, c), LOM exists in several (unrelated) languages, and a small selection is given in (2).
(2)
a. As casas foram acabadas de construir em 1950 the houses were finished to build in 1950 'They finished to build the houses in 1950.' [SW]
b. Sono-shisutemu-ga tsukai hajime-rare-ta the-system-NOM use begin-PASS-PAST 'The system began to be recognized.'

European Portuguese [Cinque 2002: 5, (7a)] Japanese [Fukuda 2007: 175, (32b)]

\footnotetext{
${ }^{1}$ Following many recent works we assume that the traditional $v \mathrm{P}$ is split into a Voice $\mathrm{P}$ and a $v \mathrm{P}$. In the remainder of this article we use the term voice/voice domain (not capitalized) as a cover term for the domain comprising of these (and possible additional) projections, whereas we use capitalized, italicized Voice(P) to refer to the label and features of a specific projection (see the text below).

Abbreviations used in this article: ACC(usative), AG(ent), AUX(iliary), AV (actor voice), DEM(onstrative), EV (epenthetic vowel), F: _ (unvalued feature), F: val (valued feature), F: val (feature valued during the derivation), FUT(ure), GEN(itive), IMPL(icit), IN(transitive), INCH(oative), INF(initive), LOM (long object movement), LV (locative voice), NOM(inative), NPL (non-plural or number-neutral), OBJ(ect), OBL(ique), PASS(ive), PAST (tense), PL(ural), POL(iteness marker), PRES(ent tense), PROG(ressive), PV (patient voice), Q(uestion marker), RC (restructuring complement), REFL(exive), RL (realis), SG (singular), SOD (spell-out domain), TOP(ic marker), TR(ansitive).
} 


\section{c. hosa man $(y) u$ - $\varnothing$ (jaanan-inda) kaTT-al(u) shurumaaD-alpaTT-itu Kannada new house-NOM (John-by) build-INF started-PASS-3.SG.N Lit: 'A house was started to be built by John' [Agbayani and Shekar 2007: 10, (1b)]}

LOM poses an interesting challenge for many accounts of restructuring and, as we will show in this article, for the voice domain in general. The dependency between the embedded object and the matrix voice properties are straightforwardly accounted for under a VP-complementation approach to restructuring as in (3) (Wurmbrand 2001). Since the embedded restructuring complement (RC) lacks a functional domain, assuming that accusative Case is assigned by a head of the voice domain, it follows that the embedded object becomes Case-dependent on the functional domain of the matrix clause.

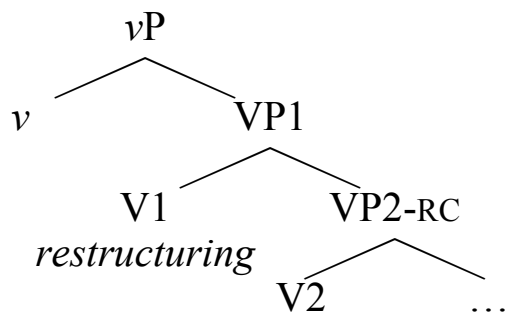

A bare VP-structure, in particular a structure without an embedded subject in a RC, is further motivated by binding properties in restructuring contexts. While non-restructuring infinitives such as the German extraposition context in (4a) allow embedded anaphors bound by a PRO subject, such anaphors are impossible when the configuration involves LOM (cf. (4b) in German, and (4c) in Japanese). The impossibility of embedded anaphors in contexts of LOM thus provides evidence for the lack of a PRO subject in such cases.

(4) a. Es wurde versucht [PRO IMPL $_{\text {sich }}$ IMPL den Fisch mit Streifen vorzustellen] It was tried [PRO IMPL REFL IMPL the fish.ACC with stripes to.imagine] 'People tried to imagine what the fish would look like with stripes.'

b. *weil sich derFisch mit Streifen vorzustellen versucht wurde 'since they tried to imagine what the fish would look like with stripes'

c. Amerika-de-wa kyodaina hanbaagaa-ga (*zibun-no) kodomo-ni America-IN-TOP huge hamburger-NOM (*REFL-GEN) child-DAT atae-tuzuke-rare-tei-ru give-continue-PASS-ASP-PAST

[Shimamura and Wurmbrand 2014: 207, (7b)] 'They ${ }_{i}$ continue to give huge hamburgers to their ${ }_{i}$ children in the US.'

However, a bare VP-complementation structure also raises several issues, among others, the question of how the embedded predicate is associated with a subject (interpretation) - the only interpretation restructuring infinitives can receive is an obligatory control interpretation. While a bare VP account (specifically a structure lacking a subject and an accusative assigning head) is advantageous in deriving LOM and the binding properties noted above, it appears to be contradicted by several properties that point to the existence of a voice domain in a RC. In this article, we address this apparent contradiction and provide a solution. We first summarize the phenome- 
na indicating that restructuring configurations involve an embedded voice domain. We then propose an account that is based on the assumption that this voice domain is deficient in a systematic way to be made precise. The new account we offer maintains the advantages of the original VP-complementation approach by also deriving a range of voice-related properties of restructuring constructions which were previously unaccounted for. ${ }^{2}$

Besides restructuring, the main goal of this paper is to provide a characterization of the general organization and featural make-up of the voice domain. Using restructuring as a probe into the composition of the voice domain, several properties are revealed which provide new or additional support for a number of voice-related assumptions. First, the distribution of restructuring supports a split voice domain (Bowers 2002, Alexiadou et al. 2006, Folli and Harley 2005, Marantz 2008, Pylkkänen 2008, Harley 2009, 2013). Second, various cross-linguistic morphological differences in the way voice properties are overtly expressed are accounted for via a cyclic spell-out approach, in which vocabulary insertion applies incrementally. We propose specific spell-out rules for the heads of the voice domain for different types of passive constructions as well as a range of restructuring phenomena in several (diverse) languages. Third, our analysis has consequences for the theory of phases - the conclusion we reach is that the phasal projection of the voice domain is the top projection of the entire domain, whichever projection that is, and that the voice domain always constitutes a phase, thus also in passive and when the voice projections are deficient. Lastly, more technically, we propose that the heads of the voice domain come with two sets of features, $v /$ Voice-features and $\varphi$-features, where the former encode voice differences such as active/passive, as well as specific flavors of the argument or event introducing heads (AGENT, CAUSER), and the latter identify a DP (the DP valuing the $\varphi$-features) as an argument of the particular voice head.

\section{Voice properties of restructuring complements}

\subsection{Subject interpretation}

As mentioned in the introduction, one question for a bare VP approach to restructuring is the interpretation of the embedded subject: in both active and passive restructuring, the agent of the matrix predicate must control the embedded agent. The examples in (5) from German involve the restructuring properties scrambling and LOM, and in both examples the embedded predicate is interpreted as involving an embedded agent interpretation identical to the matrix agent.

a. dass den Traktor der Mechaniker zu reparieren versucht
that the.ACC tractor the.NOM mechanic to repair tried
'that the mechanic tried to repair the tractor'

\footnotetext{
2 The account is an extended version of the account provided in Wurmbrand (2013b). The current version provides a more specific voice domain structure which is in line with the general research on 'little v' and covers languages/constructions that had to be set aside in the earlier version of the analysis. However, the general idea of a deficient voice domain in restructuring is the same, and certain additional advantages of this general view (e.g., the anti-reconstruction effect found in restructuring, arguments for an independent restructuring VP) can be found in the earlier article and will not be replicated here.
} 
One way to derive the interpretations of (5) is to encode the embedded subject property as part of the meaning of the matrix verb, for instance, via meaning postulates such as the following:

(6) a. $\quad \operatorname{try} y^{\prime}(\mathrm{P})(\mathrm{x}) \rightarrow \square_{\mathrm{j}} \mathrm{P}(\mathrm{x})$

Chierchia (1984a: 34)

b. whenever $x$ tries to bring about $P$, then in all the contextually relevant situations (namely those where what $\mathrm{x}$ tries actually succeeds) $\mathrm{x}$ does $\mathrm{P}$

Complex meanings such as the above, however, appear to be rather arbitrary and have the disadvantage that the syntax-semantics mapping become less transparent. Our aim is it to reduce syntax-semantics mismatches and to provide a syntax that feeds as seamlessly as possible into the interpretive component.

\subsection{Inchoative/causative alternations}

Many recent works have provided diverse evidence for a split voice domain as in (7) (see, among others, Bowers 2002, Alexiadou et al. 2006, Folli and Harley 2005, Marantz 2008, Pylkkänen 2008, Harley 2009, 2013, as well as the articles of this volume). Following these works, Voice, among others, introduces an external argument (typically an AGENT), whereas the little $v$-head encodes causation and functions as a verbalizer.

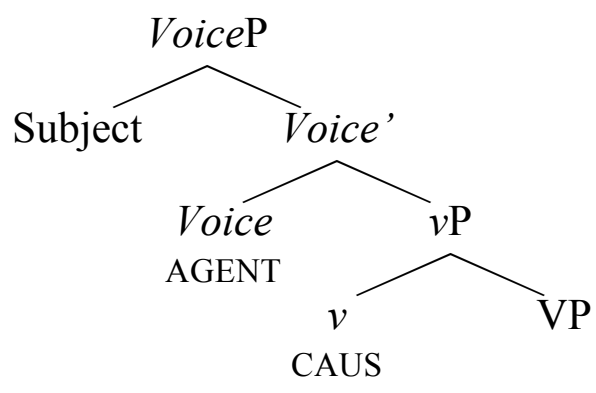

Evidence for the presence of a (layer of the) voice domain in RCs is provided by inchoativecausative alternations. We concentrate on Japanese here. ${ }^{3}$ As shown in (8), this alternation involves affixes which depend on the class of verb used (Jacobsen 1992, Kageyama 1996, Volpe 2005). One class of verbs marks the inchoative version as in (8a); another class, (8b), marks the causative version; lastly, the third class of verbs, (8c), marks both stems.
Causative
Inchoative
a. muk- 'peel'
muk-e- 'peel.off'
b. ak-e- 'open'
c. $\operatorname{sim}-\mathrm{e}-$ 'close'
ak- 'open'
sim-ar- 'close'

A prominent syntactic approach is to locate the source of this alternation in the voice domain. In line with such an approach, we propose that in Japanese, the affixes in (8) are all located in $v$. The causative structure is given in (9a), where $v \mathrm{P}$ merges with an AGENT introducing Voice head

3 Pitteroff (2014) provides an interesting argument for a richer structure of German RCs based on inchoative/causative stem allomorphy. For space reasons, we cannot discuss this argument here. 
(see e.g. Alexiadou et al. 2006, who argue following Pylkkännen 2002 that the causative version involves VoiceP in addition to $v \mathrm{P}$; see also Schäfer 2008, Pitteroff and Alexiadou 2012, Pitteroff 2014). For inchoatives, we assume that no AGENT is present, since the configuration lacks VoiceP altogether as in (9b).

(9)

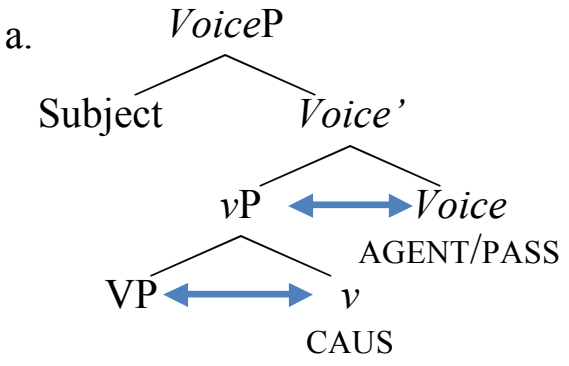

b.

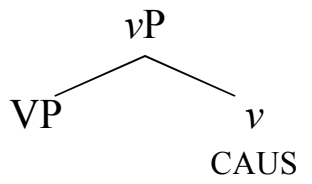

Evidence for locating both the inchoative and the causative marker in $v$ in Japanese comes from combinatorial considerations. Crucially, passive morphology occurs on top of causative morphemes as in (10), which suggests i) that there are (at least) two heads in the voice domain, and ii) that Voice (the locus of passive) is higher than the head responsible for the causative marking. The structure in (9) thus captures the distribution in (10).

$$
\begin{aligned}
& \text { ak-e- } \\
& \text { open-CAUS- } \\
& \text { 'open (transitive)' }
\end{aligned}
$$

Furthermore, since $v(\mathrm{P})$ is in a sisterhood relation with both Voice (when present) and the VP, sensitivity to both of these elements is possible. This has the advantage that the dependency of the $v$ morpheme on two factors - the type of verb and the presence/absence of Voice - can be encoded structurally (see section 3.4.3 for insertion rules).

Returning to restructuring, LOM constructions involving alternating verbs are given in (11). As shown, the embedded verbs occur with causative morphology and a bare verb stem is impossible. If, as we propose, inchoative/causative markers are realizations of $v$.CAUS, these examples provide morphological evidence for the presence of an embedded $v \mathrm{P}$ in RCs. Furthermore, the fact that only causative versions are possible and the inchoative versions are excluded supports a structure in which RCs do not just involve a $v \mathrm{P}$ but also a VoiceP. ${ }^{4}$
a.
Zyagaimo-no kawa-ga \{muk-i
/ *muk-e\}
potato-GEN skin-NOM \{peel.CAUS-EV/ *peel-caus.INCH\} -forget-PASS-PROG-PAST 'They forgot to peel the potatoes.'
b. Mado-ga $\quad$ sim-e $/ *$ sim-ar $\} \quad$-tuzuke-rare-tei-ta window-NOM \{close-CAUS / *close-INCH $\}$-continue-PASS-PROG-PAST 'They kept the window closed.'

-wasure-rare-tei-ta

\footnotetext{
${ }^{4}$ In the previous version of this article, we formulated vocabulary insertion rules for inchoative/causative alternations based on Voice, but a reviewer has made us reconsider these rules (see section 3.4.3). While our analysis suggests the presence of both Voice and $v$ in RCs, only the presence of $v \mathrm{P}$ is supported by direct morphological evidence.
} 


\subsection{Voice marking}

Although restructuring has traditionally been discussed mostly for European languages, over the last decades the empirical focus has broadened and more and more studies of restructuring in other languages have become available. Of special interest for the current paper are Austronesian languages since overt voice morphology is common in these languages. In many Austronesian languages, the verb of a RC has to occur with obligatory voice marking. An example is given in (12a) from Takibakha Bunun where the embedded verb must occur with AV (see sections 3.3 and 3.3). Furthermore, Chamorro RCs display subject agreement, which we will propose below is a property of the split voice domain. This is illustrated in $(12 \mathrm{~b}, \mathrm{c})$. Although it is difficult to show whether active constructions involve a RC or a non-deficient full voice domain (see also fn. 17), the passive example in (12c) is informative here. (12c) involves LOM, and agreement with the surface subject (the promoted object) is still possible. ${ }^{5}$ Lastly, agreement in Chamorro is sensitive to mood and the transitivity of the predicate. Crucially, in restructuring contexts, the matrix and embedded events register transitivity separately. In (12b) matrix agreement comes from the intransitive paradigm, whereas embedded agreement uses the transitive paradigm (agreement in Chamorro is very complex; see Chung 1998, 2004 for detailed motivation of these claims).

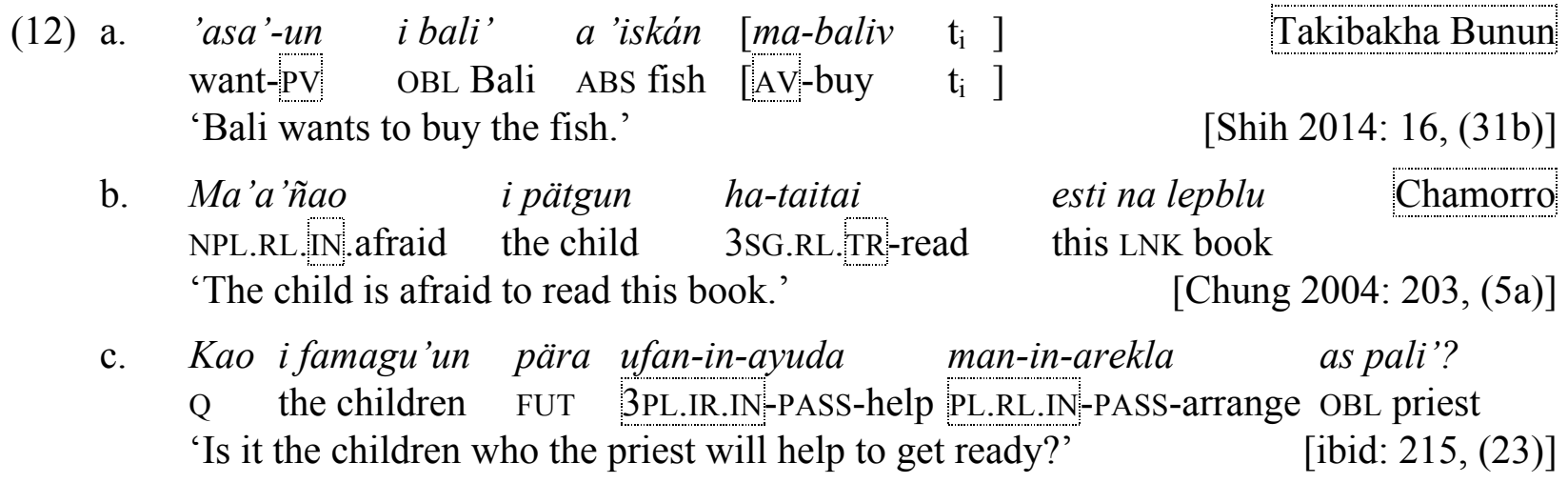

If voice marking and transitivity (as well as Chamorro-type agreement, see 3.3) are properties of the voice domain, these cases provide evidence for an existing voice domain in RCs. We return to some intricate cross-linguistic differences in the distribution of voice marking in restructuring after presenting our proposal of the composition of the voice domain.

\section{The features of the voice domain}

\subsection{Active and passive}

In a split voice domain such as (7), Voice introduces an AGENT argument (we follow Kratzer's 1996 definition of Agent* ( $\lambda$ xe $\lambda$ es[Agent(x)(e)])) or encodes PASSIVE, and, in conjunction with an AGENT feature, assigns accusative Case. We also assume that Austronesian voice marking associated with trigger arguments is a property of Voice, however, as is commonly assumed, it has to be distinguished from active/passive Voice in European languages. As proposed in Wurmbrand (2013b), this difference does not require different projections but can be implement-

\footnotetext{
${ }^{5}$ In many cases given in Chung (2004), embedded agreement is missing in the RC due to independent properties on agreement in Chamorro (see section 3.3).
} 
ed via different types of features. The head $v$ functions as a verbalizer, marks transitivity (TR/IN), and encodes meanings such as CAUS or BECOME (possibly others; Folli and Harley 2005). In this paper, we simply note these features under the respective head of the voice domain as in (13). ${ }^{6}$ In addition to voice features, we propose that Voice also has interpretable $\varphi$-features, which can be inserted unvalued (notated as F: __ ) or valued (see below). In contrast, $v$ typically does not have $\varphi$-features, unless certain agreement properties are observed to which we return in section 3.3.7

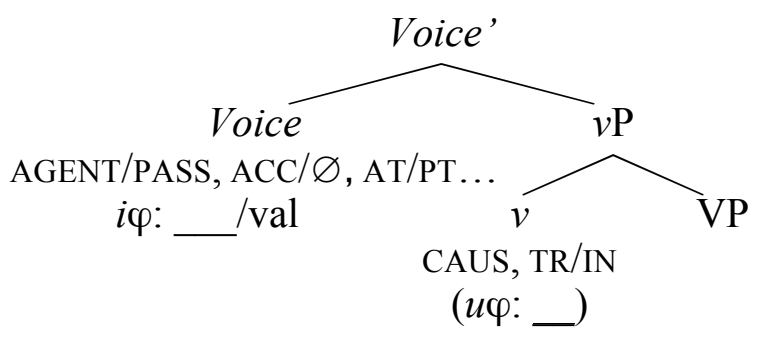

We adopt a valuation based feature sharing approach to Agree (Pesetsky and Torrego 2007), however formulated as the downward (Reverse Agree) mechanism in (14) (see Wurmbrand 2014a for other Reverse Agree approaches).

(14) A feature $F$ : _ on $\alpha$ is valued by a feature $F$ : val on $\beta$, iff

[Wurmbrand 2014a]

i. $\quad \beta$ c-commands $\alpha$ AND

ii. $\quad \alpha$ is accessible to $\beta$. [accessible: not spelled-out]

iii. $\alpha$ does not value $\{$ a feature of $\beta\} /\{$ a feature $F$ of $\beta\}$.

To illustrate our system, consider the derivation for active constructions in (15). Since Voice is inserted with an AGENT feature, it also carries an ACC feature which can Case-license an object. Depending on the type of VP, $v$ is inserted either with or without a CAUS feature-change of state predicates typically combine with a CAUS $v$, whereas non-change of state predicates do not involve a CAUS feature in $v$ (however, $v$ still functions as a verbalizer and can involve a transitivity feature). Voice is inserted with unvalued $i \varphi$-features, and as a consequence, a DP must be merged to value these features. We propose that valuation of interpretable $\varphi$-features and feature sharing between a DP and Voice.AGENT corresponds to traditional theta-assignment, i.e., the DP in Spec,Voice P is interpreted as the AGENT of the $v \mathrm{P}$. Since $\varphi$-feature valuation on Voice corresponds to an argument-of relation, two different DPs must be merged in (non-reflexive) transitive constructions to derive the different theta-relations carried by the subject and object.

\footnotetext{
${ }^{6}$ As is shown in more detail in 3.3 (see in particular (30)), (in)transitivity (like the causative/inchoative alternation) references both Voice (whether or not there is an AGENT) and the VP (whether or not there is an object). We thus assume that $\mathrm{TR} / \mathrm{IN}$ is a property of $v(\mathrm{P})$, which is in a local dependency with both Voice and VP.

${ }^{7}$ We thank Marcel Pitteroff for pointing out issues with our previous assumption that $v$ also has $\varphi$ features.
} 


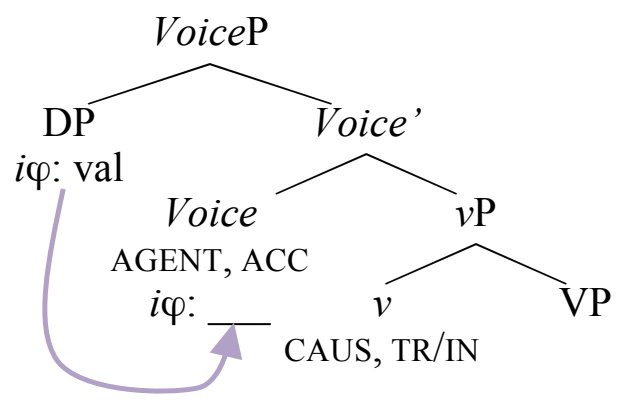

The basic passive derivation is given in (16). Voice is inserted with a PASs feature and, following Legate $(2010 \mathrm{~b}, 2012)$, with lexically valued $i \varphi$-features corresponding to the implicit AGENT (see 3.3 and 3.4.2 for evidence). Since Voice is inserted fully valued, no (non-oblique) subject is merged. Only Voice. AGENT has the potential to assign ACC, thus objects cannot be Case-marked within the voice domain but become Case-dependent on the T-domain. ${ }^{8}$ Lastly, we propose that morphological selection is derived via (uninterpretable) V-features which get valued under Agree with a higher voice or inflectional head, thereby feeding the selected value into PF. For instance, if $v / \mathrm{V}$ is valued by $\mathrm{T}$ with the feature $i \mathrm{~T}$ :PAST, V:PAST spells out as past tense on the verb (see Wurmbrand 2012, 2014a for a detailed account of morphological selection). In passive contexts, (16), the V-feature on $v / \mathrm{V}$ is valued V:PAss by Voice, which, in English, spells out as participial morphology on $\mathrm{V}$ (features valued during the derivation are underlined). More specific PF realization rules will be provided in the course of this article. ${ }^{9}$

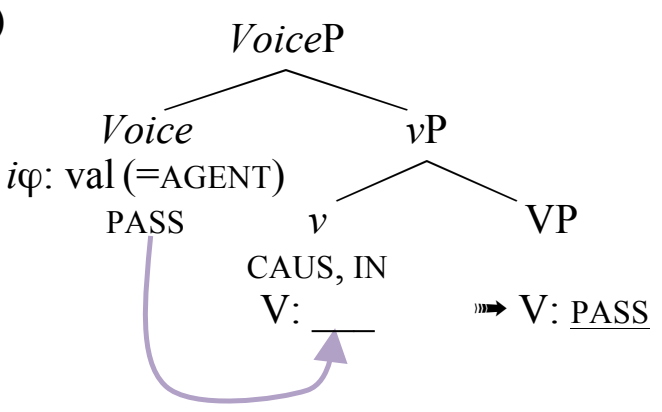

Passive falls, broadly, in two classes: morphological and periphrastic passive. Norwegian is a language which allows both types of passive, as illustrated in (17).
a. Ballen blir
blir
sparket (av elevene)
the.ball be(come).PAST kick.PART (by the.pupils)
'The ball was kicked (by the pupils).'

Norwegian

[T. Lohndal, p.c.]

\footnotetext{
${ }^{8}$ In what follows, we notate the lexically inserted $\varphi$-features in passive as $i \varphi:$ val $_{\mathrm{AG}}$. Note that this is just a shortcut for the semantic relation between PASS \& the $i \varphi$-features, yielding the implicit AGENT interpretation, and does not mean that there is an actual AGENT present syntactically.

${ }^{9} \mathrm{In}$ active contexts, the $\mathrm{V}$-value is determined by an aspectual, modal, or temporal head above Voice, if Voice.AGENT does not occur with any voice morphology. There are certain intricacies for deriving active contexts without auxiliaries in our account. Generally, if $v$ is not valued within the VoiceP, we would assume that $v$-incorporation takes place.
} 


\section{b. Ballen sparkes (av elevene) \\ the.ball kick.PASS (by the.pupils) \\ 'The ball was kicked (by the pupils).'}

Before laying out our analysis of the two types of passive, a few words about syntactic domains and spell-out are necessary. We follow the assumption that the voice domain is a phase, but that in a split voice structure it is not $\nu \mathrm{P}$, but Voice $\mathrm{P}$ (the top projection of the voice domain) that constitutes a phase. During transfer of a phase, the complement of the phase-head is spelled out (it constitutes a spell-out domain [SOD]), and interpretable and uninterpretable features are sent to the LF and PF interfaces, respectively. If a feature in a SOD has not received a value, the interfaces cannot handle it, and the derivation is cancelled.

We propose that the core difference between morphological and periphrastic passives is whether the $v$-head incorporates into Voice or not. The derivation for periphrastic passive is given in (18). After Voice is merged and Agrees with $v$, the $v \mathrm{P}$ is spelled out as a participle (we ignore here possible movement of $\mathrm{V}$-to- $v$; if there is no movement, the participial morphology lowers onto V at PF). The specific spell-out rules we propose are in (19). The rules are ordered and higher (more specific) rules apply before lower rules. Crucially, the rules are insertion rules which apply only within SoDs. Since in (18), at the time $v \mathrm{P}$ is spelled out, $v$ is not in the same domain as Voice (Voice is the phase head and as such only spelled out when the higher phase is complete), rule (19a) cannot apply but rule (19a') must be used (-PARTICIPLE stands for whatever the participle affix is in a language-e.g., -en/ed in English). When the next phase is completed, Voice is spelled out, and since in this SOD, Voice is not in the context of $v(v \mathrm{P}$ has already been spelled out in the first cycle), rule (19b) cannot apply and instead the Voice head is spelled out separately as the passive auxiliary, as stated in (19b'). ${ }^{10}$

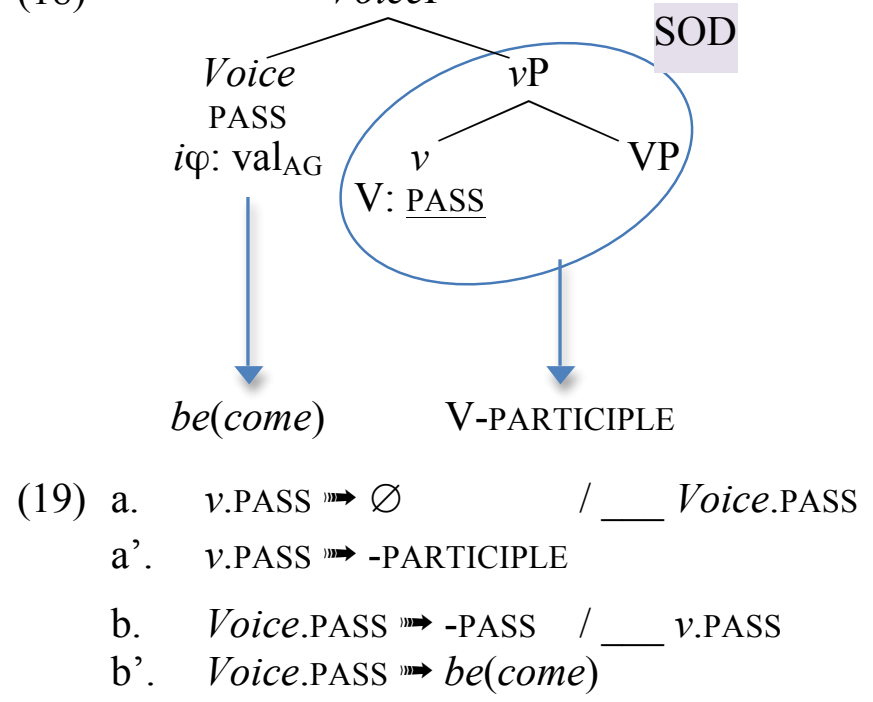

In contrast to periphrastic passive, we propose that morphological passive involves incorporation of $\mathrm{V}$ into Voice (via $v$ ), as shown in (20). When $v$ combines with VP it still verbalizes the root

\footnotetext{
${ }^{10}$ An alternative to the SOD approach here is to derive periphrastic/morphological passive via morphological locality as in Bobaljik (2012) where it is argued that the trigger for a morpho-phonological rule (including vocabulary insertion) must be inside the same complex head (see also Thornton 2015).
} 
(and possibly is marked for transitivity), but incorporation essentially has the effect that it 'holds off' spelling out $\mathrm{V}$ and $v$. Technically, incorporation removes $v$ and $\mathrm{V}$ from the $v \mathrm{P}$ SOD as follows: when the Voice P phase is complete, there are two copies of $\mathrm{V}$ and $\mathrm{V}+v$, and as part of the copy choice mechanism at transfer, the lower copies of these heads are deleted (in the diagram, we simply indicate deleted copies as traces). The $v \mathrm{P}$ is thus spelled out without $v$ and $\mathrm{V}$. $\mathrm{V}+v+$ Voice are spelled out only when the next phase is completed. In the higher phase, $v$ ends up in the same SOD as Voice, and since both have passive features, rule (19a) applies, which preempts the application of the rule in (19a'). The $\mathrm{V}+v$ head is hence realized as the bare verb stem. Similarly, since Voice is now in the same SOD as $v$, the rule in (19b) applies and Voice is realized as a passive affix rather than a passive auxiliary.

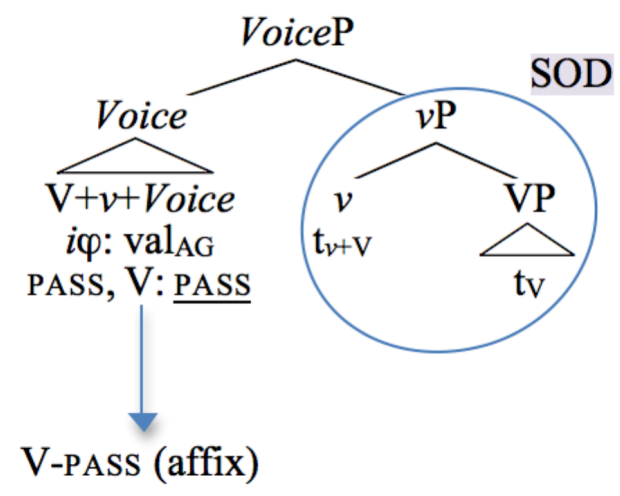

How is it determined whether a language employs option (18a) or option (18b), or, as in Norwegian, either option? Since the nature of affix vs. independent auxiliary is a lexical property, we propose that the trigger of incorporation comes with the PASS feature itself. In morphological passive languages, the PASS feature in Voice comes with an EPP property which triggers movement of $v(+\mathrm{V})$. We refrain from further deriving this property but just state it as an assumption here. In a language like Norwegian, the EPP feature would be optional, or in other words, there would be two lexical items PASS. Importantly, incorporation is not necessarily an inherent property of Voice, nor of a specific language in general-rather it can be a lexical property of the passive feature itself. We will show that this approach has advanatages when it comes to incorporation in restructuring.

\subsection{Restructuring}

The main claim of this paper (following Wurmbrand 2013a) is that voice restructuring is encoded as the existence (languages allowing LOM) vs. absence (languages prohibiting LOM) of a special Voice head, Voice $_{\mathrm{R}}$, which is inserted unvalued as in (21). The lack of a Voice value-AGENT or PASS - prohibits merging a subject and ACC Case. Thus, the lack of PRO and the lack of Case for the embedded object, the two core properties of LOM, follow. However, something else needs to be said about the structure in (21). If the $v \mathrm{P}$ is sent to spell-out as is in (21), the unvalued Vfeature would cause a problem. We propose that there are two strategies for valuing the $\mathrm{V}$ feature, which will correctly derive the two types of voice restructuring languages attested. 


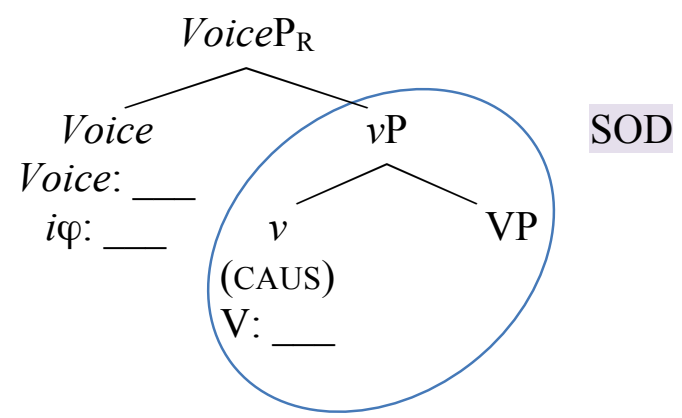

The first strategy, (22), involves V-to-v-to-Voice incorporation, which removes the verb and the $v$-head from the lowest SOD. The unvalued features of $v$ hence do not reach spell-out in the first cycle but get a chance to be valued by heads in the next phase. We will show that this strategy yields voice matching between the matrix and embedded predicates, which is attested in several languages (see section 3.3). Although further investigation of properties other than passive and restructuring are necessary, we hypothesize that in voice matching languages, the trigger for incorporation is tied to the Voice head itself, and not just to a feature of Voice (such as passive). Thus incorporation occurs whenever Voice is present, independently of the value of Voice.

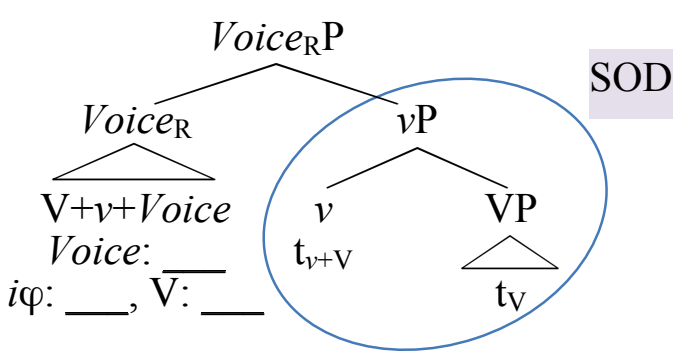

The second strategy is to insert a default/dummy value in the Voice head as in (23). ${ }^{11}$ This value is then transmitted to $v$ via Agree, and at spell-out, the appropriate (language specific) default form is realized as the $v$ value on the verb. ${ }^{12}$ Note that our account in (23) predicts - correctly, as we will show in section 3.4 that RCs in default voice languages can still occur with $v$ values such as CAUS, since only restructuring Voice is deficient, but $v$ is not.

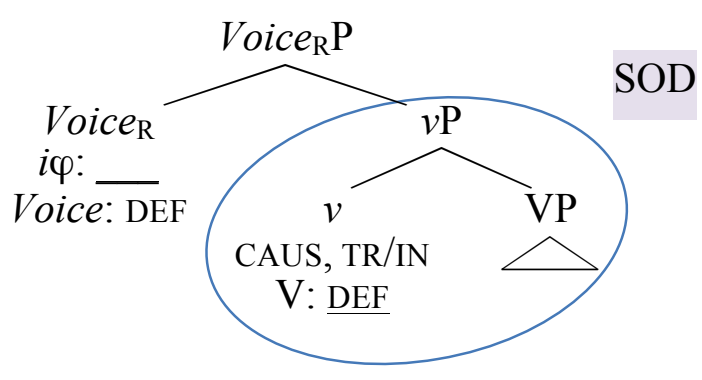

\footnotetext{
11 The analysis of default voice languages has been changed from the previous version of this article due to the valuable input from a reviewer, Jonathan Bobaljik, Marcel Pitteroff, who all urged us to reconsider certain earlier assumptions and offered helpful alternatives which lead to the current analysis.

${ }^{12}$ It is tempting to use the concept of Schäfer's (2008) expletive Voice (also Pitteroff 2014) as the value of Voice $_{\mathrm{R}}$ head in default voice languages. As pointed out by a reviewer, this may be difficult, however, since there are languages like Greek which arguably have expletive Voice but no restructuring Voice. We leave a full typology of Voice values for the future.
} 


\subsection{Voice matching: Chamorro and Isbukun Bunun}

Voice matching is illustrated in (24) for Chamorro and Isbukun Bunun. The examples in (25) from Chamorro show that all mismatching options - cases where the matrix and embedded voice differ-are excluded.
a. Pära tafan-ma-chägi ma-na'fanätuk ni lalahi siha FUT 1PL.IR.IN-PASS-try NPL.RL.IN.PASS-hide OBL men PL 'The men will try to hide all of us.'
[Chung 2004: 204, (6a)]
b. Iliskinun-ku bunbun-a tu baliv-un
want.PV-1SG.ACC
banana-that. NOM
$\mathrm{TU}$ buy-PV
Isbukun Bunun
'I wanted to buy the bananas.'
a. *Tinituhun
ha-lalatdi
si Dolores
i famagu'un
Chamorro
NPL.RL.IN.PASS.begin 3sG.RL.TR-scold
'Dolores began to scold the children'
[Chung 2004: 219, (32a)]
b. *Tinituhun
kumati
i pätgun
NPL.RL.IN.PASS begin NPL.RL.IN.cry the child
'The child began to cry.'
[ibid. (32b)]
c. *Ha-hähassu
si Carmen binisita
3SG.RL.TR-think.PROG
Carmen
i biha
'Carmen is thinking of visiting the old lady.'
d.
Q
man-sinedda' ifamagu'un
i famagu'un ni chi'lu-hu?
Q 3SG.RL.TR-help PL.RL.IN-PASS: find the children
'Did my brother help find the children?'
OBL sibling-1SG
[ibid: 222, (37a)]

The structure for (24) is given in (26).

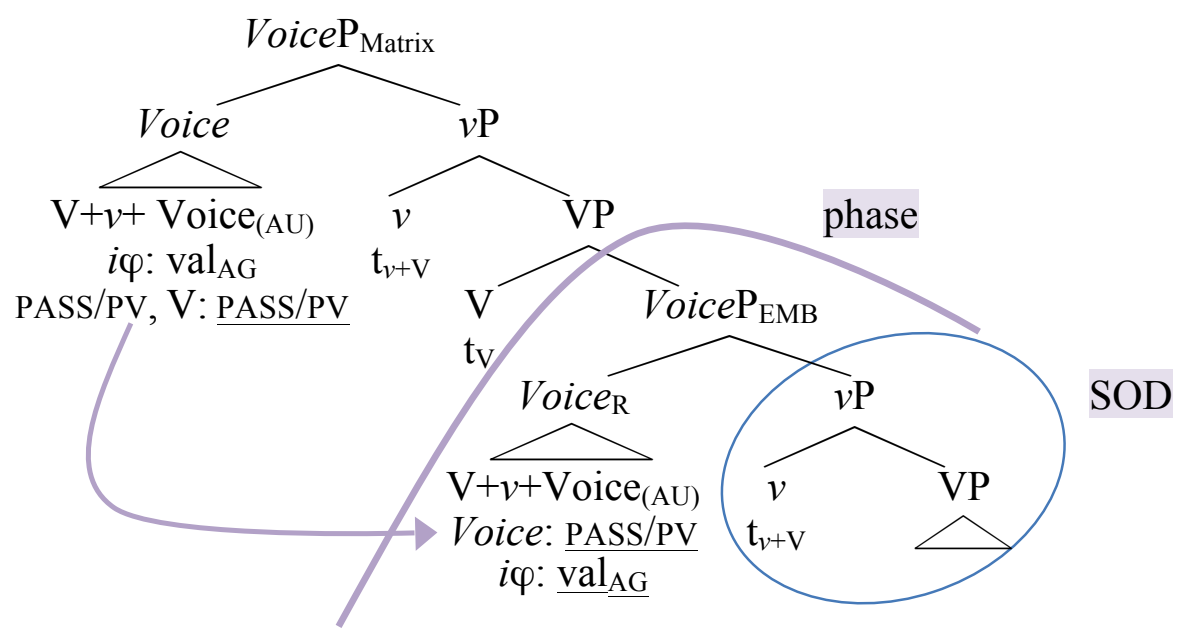

To distinguish Austronesian voice marking from active/passive voice in European languages, we use the diacritic Voice $_{\mathrm{AU}}$ which indicates that this is possibly a different type of feature (see Wurmbrand 2013b). For the current approach, it is not necessary to commit to a specific account 
of Austronesian voice marking, the only important assumption is that (at least part of) the trigger marking is a property of the Voice domain. As shown, Voice is spelled out together with the corresponding $v(+\mathrm{V})$ heads, which is made possible by (V-to-) $v$-to-Voice incorporation. Although the matrix and embedded Voice complexes are part of different soDs, they match since the embedded Voice $\mathrm{P}$ is headed by Voice $_{\mathrm{R}}$ which is inserted unvalued and therefore must establish a feature dependency with matrix Voice, resulting in feature sharing.

A crucial aspect of our account is that the $\varphi$-features of embedded Voice $_{\mathrm{R}}$ are valued by the $\varphi$-features of the matrix subject or matrix Voice (PASS/PV). In matrix PV constructions, like in passive, the $\varphi$-features of Voice are inserted valued, with the values corresponding to the implicit AGENT. An AGENT can then only be realized as an oblique argument as in (24a). Since Agree involves feature-sharing, the semantic $\varphi$-values of matrix Voice and embedded Voice $_{\mathrm{R}}$ are shared (recall that the $\varphi$-features on Voice are interpretable), which we propose corresponds to coreference, thereby deriving the obligatory control relation. ${ }^{13}$

There are several morphological properties of Chamorro restructuring which provide further support for our general approach. First, as discussed in Legate (2010a, 2014), Chamorro offers evidence for the claim that the features of the implicit AGENT are present on Voice. Chamorro has two passive morphemes: the prefix $m a$ - and the infix -in- (plus some phonologically triggered variants of these morphemes). The choice between these two affixes depends on the features of the (implicit) AGENT, and crucially not the surface subject. The prefix $m a$ - is used when the understood AGENT is plural (cf. (24a)), whereas the infix -in- is used when the AGENT is singular as in (27a) (see Chung 1998, 2004; we have changed the glosses to reflect these properties). In particular in (27b), only the implicit/oblique AGENT the students is plural whereas the surface subject the teacher is singular, but the passive morpheme must be the affix specified for plural, i.e., for the features of the implicit/oblique AGENT. The structure in (26) straightforwardly derives the AGENT conditioned allomorphy of the passive morpheme, since Voice is specified for the features of the AGENT, which are thus visible when vocabulary insertion of PASS takes place.
a.
Hagu pära un-tinituhun
in-änña
ni nana-n Joaquin
you FUT 2SG.IR.IN-PASS.AG.SG begin PASS.AG.SG-beat
OBL mother-LNK Joaquin
'Joaquin's mother is going to begin to punish you.'
[Chung 2004: 219,(31b)]
b.

$\begin{array}{lll}\text { Ma-hähassu } & \text { ni istudianti } & \text { ma-bisita } \\ \text { PASS.AG.PL-think.PROG OBL students } & \text { PASS.AG.PL-visit }\end{array}$
i ma'estra
the teacher
'The students are thinking of visiting the teacher.'
[ibid: $228,(44 a)]$

Furthermore, as mentioned in section 2.3, Chamorro RCs also involve subject agreement in LOM contexts as in (12c), repeated in (28a) with the structure in (28b). Since VoicePs are phases in our account, ${ }^{14}$ and since ACC is only present when Voice contains an AGENT feature, neither VoiceP in (28b) includes a structural Case assigner, and objects must occur at least at the edge of the matrix VoiceP (or higher) to escape spell-out with an unvalued Case feature. Chamorro agreement provides evidence for this derivation, and hence indirectly also for the phasal status of passive VoicePs. We propose, as shown in the diagram, that in Chamorro, exceptionally, both heads of

\footnotetext{
13 Technically, this can be achieved if agreement features are linked to a semantic index.

14 This applies to active and passive VoicePs (see Legate 2003, Sauerland 2003, Alexiadou et al. 2014, Wurmbrand and Haddad To appear).
} 
the voice domain-Voice and $v$-have $\varphi$-features. While the $\varphi$-features of Voice are interpretable and linked to theta-assignment, the $\varphi$-features of $v$ are purely morphological, i.e., uninterpretable in our approach. As a result, only the latter can be valued by an underlying object moving through the edge of the embedded VoiceP, which we suggest is how subject agreement arises in Chamorro. ${ }^{15}$ As shown in (28b), the object undergoes cyclic movement through all phase edges (driven by its need of Case), and at the point when it occurs in the embedded Spec,VoiceP, it values the $\varphi$-features of $v$ (which has undergone incorporation into Voice $e_{\mathrm{R}}$ ). Valuation of the $\varphi$ features of Voice by the object is not excluded at this point, but such a derivation would lead to theta-violation since sharing of the interpretable $\varphi$-features leads to the object being (also) interpreted as the AGENT, which we assume is filtered out at the LF interface. Lastly, the order $v$ Voice-V in (28a) is established by post-syntactic reordering (see e.g. Arregi and Nevins 2012; $v$ and Voice are both prefixes and hence procliticize onto the root). Alternatively, it may be the case that in Chamorro, only $v$-incorporation takes place, stranding the verb.
a. Kao ifamagu'un pära ufan-in-ayuda
man-in-arekla
as pali'?
Q the children FUT BPL.IR.IN-PASS-help PL.RL.IN-PASS-arrange OBL priest

'Is it the children who the priest will help to get ready?'

[Chung 2004: 215, (23)]

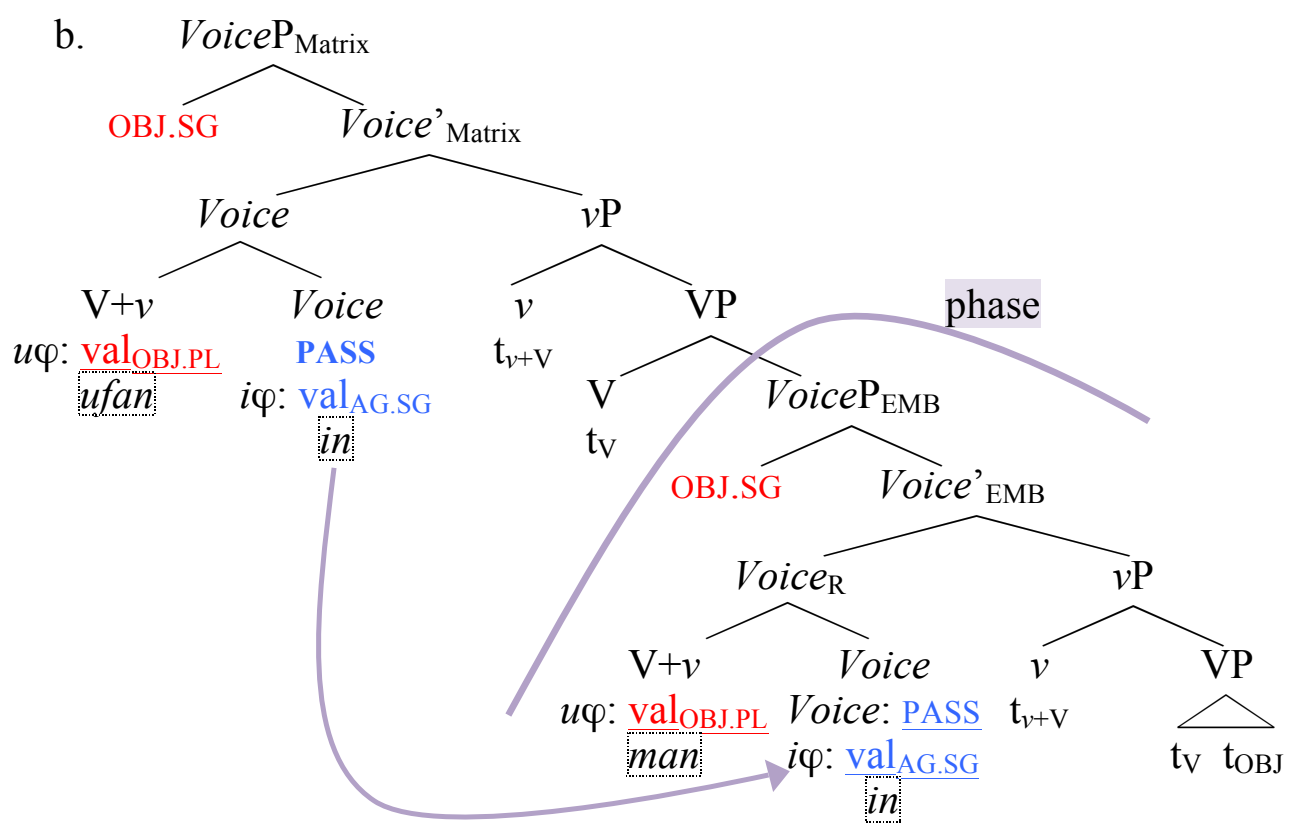

The 'double' agreement effect we find in (28) thus provides evidence for independent sets of $\varphi$ features on Voice and $v$. There are two further properties that support the analysis of subject agreement as $\varphi$-valuation of $v$ rather than Voice in Chamorro. First, as mentioned in section 2.3, Chamorro subject agreement is conditioned by mood and transitivity. ${ }^{16}$ In restructuring contexts,

\footnotetext{
${ }^{15}$ Locating agreement in the voice domain is also proposed in Béjar and Rezac (2009). At this point, since agreement is not typically found in RCs (Chamorro seems exceptional), we treat it as a special case and assume that $\mathrm{v}$-features are not usually present on $v$. However, as noted by a reviewer, many interesting issues arise, which we reserve for the future.

${ }^{16}$ As discussed in Chung (2004), agreement in RCs always uses the realis paradigm, independently of the
} 
the matrix and embedded events register transitivity separately. In (29a) (repeated from (12b)), matrix agreement comes from the intransitive paradigm, whereas embedded agreement uses the transitive paradigm. The opposite is the case in (29b): the verb begin is transitive in Chamorro (S. Chung, p.c.; when begin occurs with an eventive NP as in (29c), a reflexive configuration is used), hence matrix agreement chooses the transitive form, whereas the embedded verb is intransitive and agreement is chosen from the intransitive paradigm.

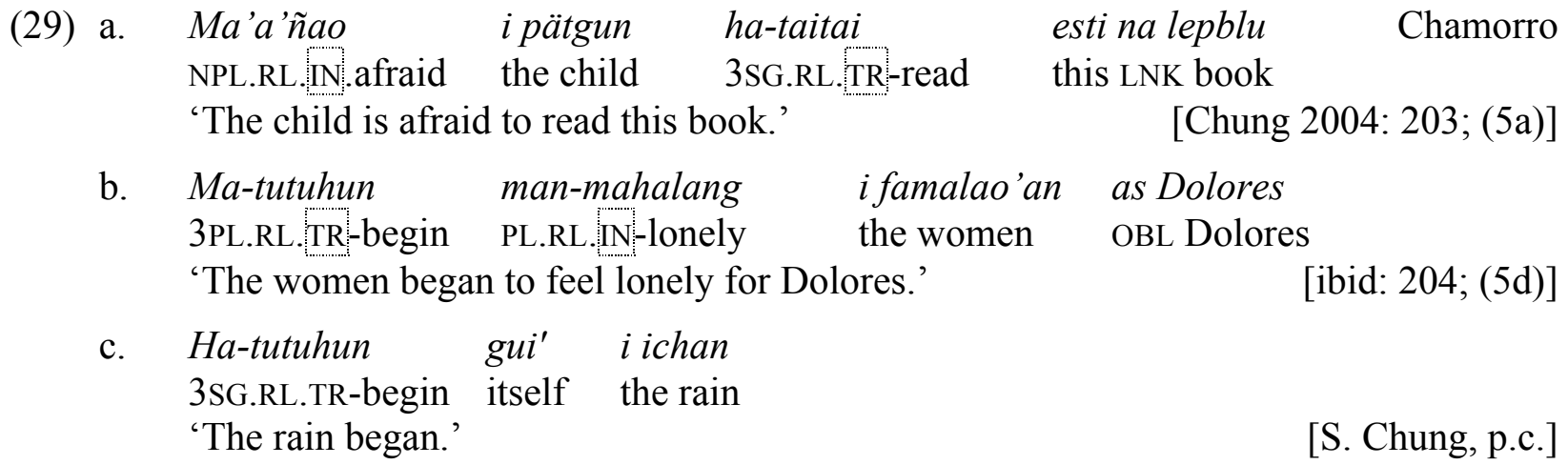

Since transitivity is a relation between Voice and the argument structure of the VP, we assume that, similar to the causative/inchoative alternation, transitivity is a property of $v$ as in (30) (this is in line with approaches such as Collins 1997 and Bowers 2002, which propose an explicit $\mathrm{TrP}$ ). If subject agreement is the realization of $\varphi$-features on $v$ in (30), as we suggest, it follows that subject agreement is conditioned by (in)transitivity since $v$ contains both-features corresponding to (in)transitivity and the subject's $\varphi$-features.

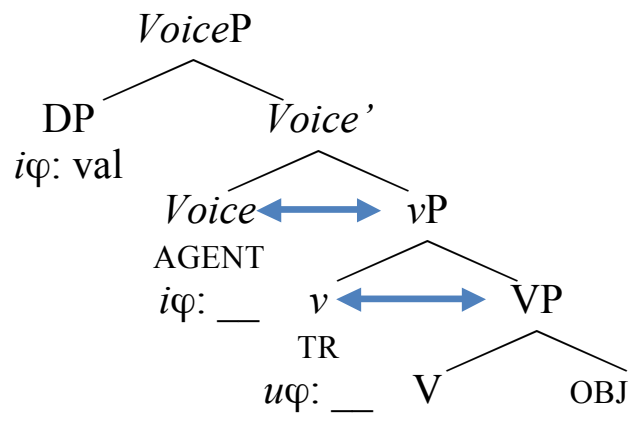

Second, in RCs with LOM, subject agreement is often non-overt. In part, this is due to a conspiracy of various agreement-related properties in Chamorro (for instance, in realis forms, singular agreement can be unpronounced; see also Chung 1998). However, for cases such as (27a), repeated in modified form in (31), S. Chung (p.c.) points out that the verb ma-na'fan-ätuk is more complex in that it involves a causative and agreement attached to the causative. While the order of affixes in (31) is not immediately accounted for by a structure involving incorporation as in (28b), the items involved express exactly the features we have proposed: a Voice head referencing the implicit AGENT and a $v$.CAUS agreeing with the surface subject (the underlying object). This finer grained structure hence supports our general make-up of the voice domain, even if the order of affixes requires some additional fine tuning.

interpretation. Since RL does not correspond to semantic mood, we assume that no $\operatorname{Mood}(\mathrm{P})$ is present in RCs, and that RL-agreement is the default. 


$$
\begin{aligned}
& \text { Pära tafan-ma-chägi ma-na'-fan-ätuk ni lalahi siha } \\
& \text { FUT 1PL.IR.IN-PASS.AG.PL -try PASS.AG.PL-CAUS-PL.OBJ-hide OBL men PL } \\
& \text { Lit. 'We will be tried to be caused to be hidden by the men.' }
\end{aligned}
$$

'The men will try to hide us.'

[S. Chung, p.c.]

\subsection{Default voice languages}

In contrast to voice matching languages, default voice languages display voice properties in RCs which differ from the voice of the matrix predicate. We discuss four types of default voice languages.

\subsubsection{Mayrinax Atayal and Takibakha Bunun}

The first group of languages involves languages like Mayrinax Atayal and Takibakha Bunun, which display the typical Austronesian voice marking. Crucially, in RCs, the embedded predicate must be marked with AV as in (32a-c), and embedded PV is prohibited, no matter what the voice of the matrix predicate is $(\mathrm{cf} .(32 \mathrm{~d}, \mathrm{e})) .{ }^{17}$
a. 'asa'-un ibali' a 'iskán [ma-baliv $\mathrm{t}_{\mathrm{i}}$ ] want-PV OBL Bali ABS fish [AV-buy $t_{i}$ ]
'Bali wants to buy the fish.'
Takibakha Bunun
b. naqaru.un $i \quad$ t.um.uting ni yumin $k u$ bawwak
finish.PV LNK beat.AV beat GEN Yumin NOM pig 'Yumin finished beating/killing the pigs.'
c. m.naqru $i$ t.um.uting cu bawwak i yumin
AV.finish LNK beat.AV beat ACC pig NOM Yumin
'Yumin is finishing beating/killing pigs.'
[Shih 2014: 16, (31b)]
Mayrinax Atayal
[Chen 2010: 5]
d. *naqaru.un $i$ tuting.un ni yumin kubawwak finish.PV LNK beat.PV GEN Yumin NOM pig

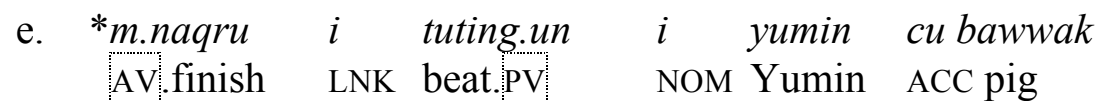
[ibid: 7]
[ibid: 11]
[ibid: 11]

An important observation made in Chen (2010) is that the embedded AV in RCs cannot be treated as a true AV form, but constitutes a default voice. We replicate one of Chen's arguments here. In Mayrinax Atayal, like in many other Austronesian languages, A'-extraction of the object is only possible when the verb occurs in the PV. The blocking effect of AV is illustrated in $(33 a, b)$ for

\footnotetext{
${ }^{17}$ Shih (2014) argues that there are two types of restructuring constructions in Takibakha Bununconstructions involving a reduced voice domain, and constructions involving a full voice domain. Since the latter block clitic climbing, these constructions may not involve any restructuring beyond the omission of the tense and C-domains. Wurmbrand $(2014 \mathrm{~b}, \mathrm{c})$ argues for a distinction between voice restructuring (the embedded complement involves a deficient voice domain) and size restructuring (the embedded complement involves a full voice domain but no TP and/or no CP). Since only the former is relevant for the current paper, we omit a discussion of size restructuring here and only consider the constructions analyzed as voice restructuring (i.e., what Shih 2014 refers to as matrix non-AV constructions).
} 
extraction in simple clauses, and (33c) for extraction from an embedded (non-restructuring) clause. Importantly, in RCs, AV is possible (in fact necessary) in the embedded predicate as shown in (33d). The fact that AV does not block object extraction in restructuring contexts, whereas it does so in simple clauses and non-restructuring contexts, thus provides evidence for AV not being a true voice.

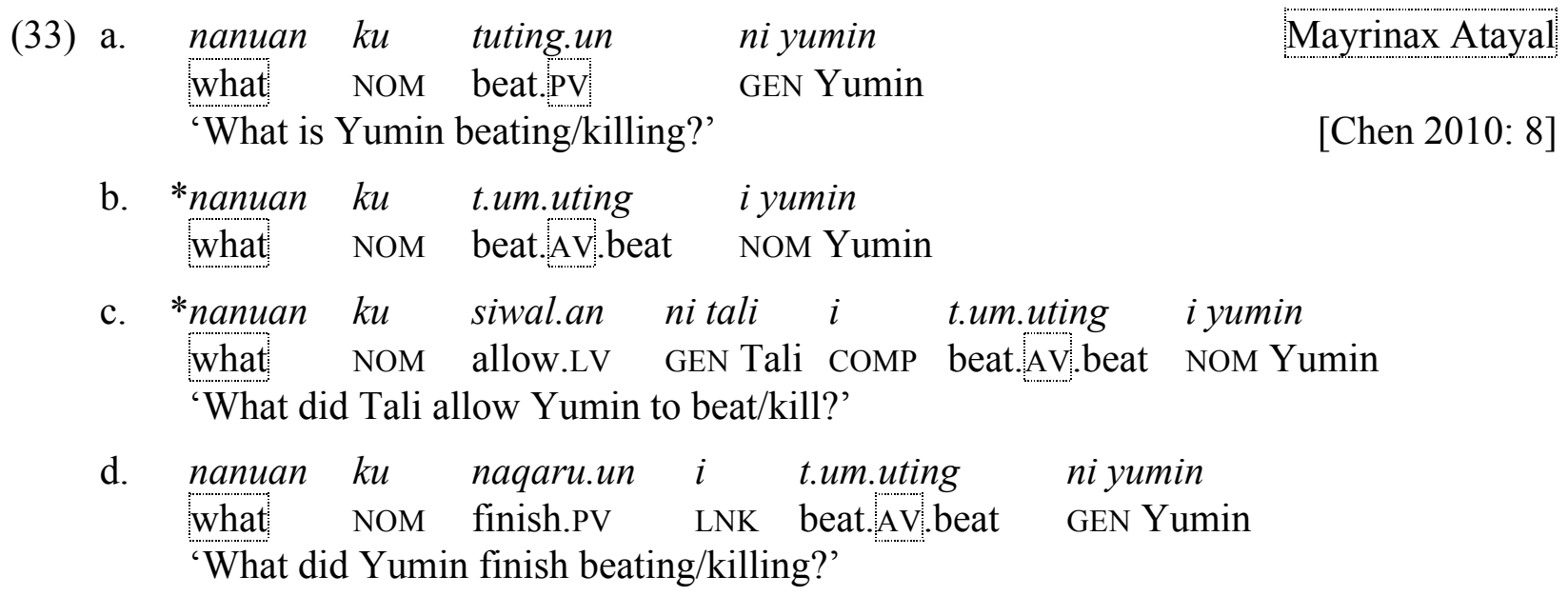

A similar argument can be made based on the distribution of clitics. In Mayrinax Atayal, there are no ACC clitics. In simple clauses, object clitics are hence only possible when they are NOM, which in turn requires that the verb occurs in PV. Crucially, in RCs with clitics, the lower verb must still occur in the AV form, showing again that this voice is not a true AV but rather a default voice.

Having established that the embedded AV in cases such as $(32 a, b)$ is default voice, let us now turn to the structure of these constructions.

(34) a.
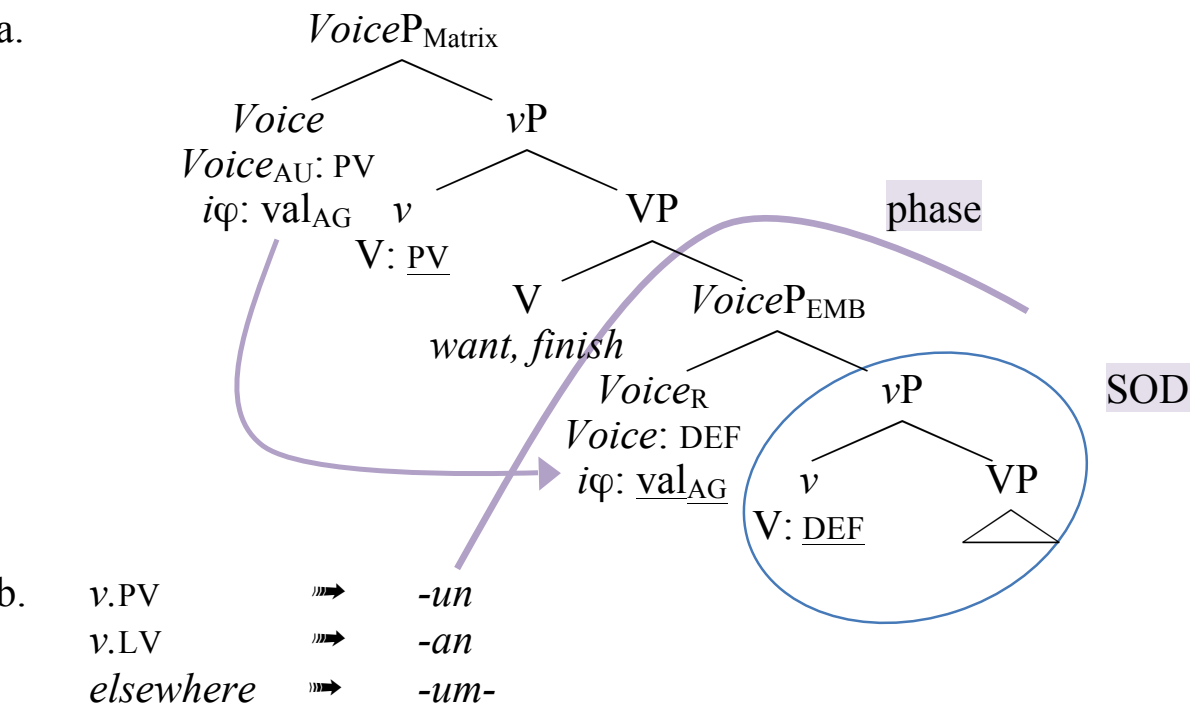

As shown in (34a), Voice $_{\mathrm{AU}}$ is a feature of Voice and its value is transferred to $v / \mathrm{V}$ via the unvalued $\mathrm{V}$ : _ feature on $v / \mathrm{V}$. Morphologically Voice $_{\mathrm{AU}}$ is spelled out on the verb, but syntactically, it is in Voice, thus any movement triggered by Voice $_{\mathrm{AU}}$ targets Spec, VoiceP. The insertion rules for Mayrinax Atayal are given in (34b). The rules are defined such that the 
elsewhere case corresponds to the AV form, hence this form is used in restructuring contexts, where Voice $_{\mathrm{AU}}$ has no specific value. Finally, the lack of a Voice value prohibits merging an embedded AGENT (cf. the OBL/GEN in $(32 \mathrm{a}, \mathrm{b})$, and the sharing of $i \varphi$ values on matrix and embedded Voice is again the source for the semantic control relation.

\subsubsection{Acehnese}

The same analysis is provided for Acehnese, which provides further pieces of support for our approach. As shown in (35), Acehnese verbs occur with a prefix marking politeness and person features of the agent argument. Legate $(2012,2014)$ argues that the prefix is a realization of Voice, which we propose has $\varphi$-features valued by the AGENT.
Aneuk miet nyan meu-tingkue lé kamoe child small DEM 1.EXCL-carry by 1.EXCL 'The child is carried by us.'
b. Aneuk miet nyan neu-tingkue lé droeneuh child small DEM 2.POL-carry by 2.POL
'The child is carried by you.'
c. Aneuk miet nyan geu-tingkue lé gopnyan child small DEM 3.POL-carry by 3.POL 'The child is carried by him/her.'

[Legate 2012: 497, (3a)]

[ibid. (3b)]

[ibid. (3c)]

Legate (2014) also provides arguments for a split voice domain. While unergatives and nonchange of state predicates do not realize any $v$ morphology (such as CAUS), (certain) transitive change of state predicates occur with the causative morpheme peu- ( $p u$ - before bilabials), as in (36b). Importantly, these verbs still occur with AGENT-marking Voice morphology, thus supporting a split Voice- $v$ domain.

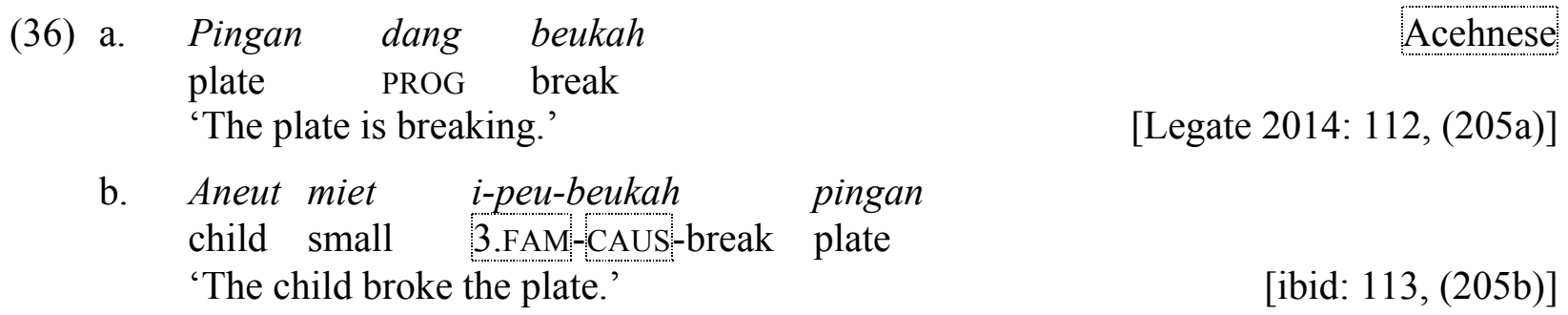

Returning to restructuring, Legate's crucial observation is that no Voice marking is possible on the embedded verb (neither the agent prefix nor AV/PV marking), however, a causative can appear in a LOM restructuring configuration, as shown in (37).

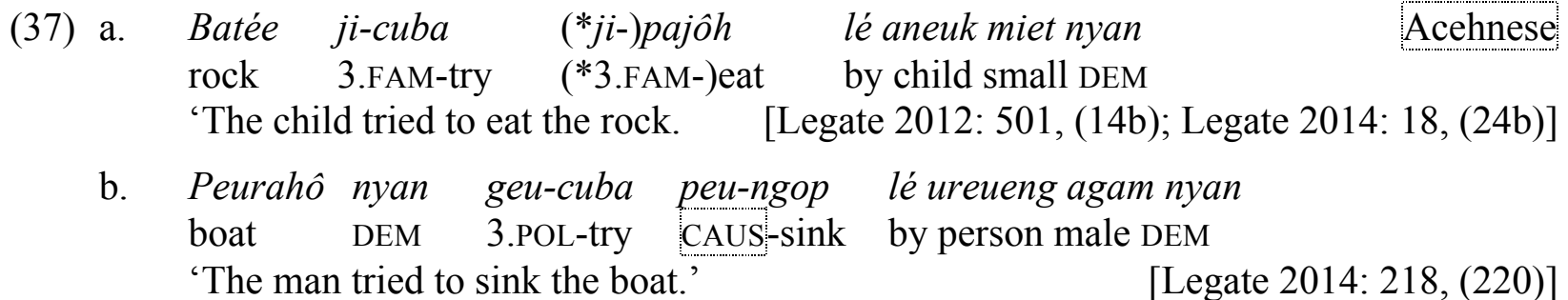


Our analysis for (37) is given in (38). Since Acehnese follows the default voice strategy, Voice $_{\mathrm{R}}$ is merged with a dummy/default value. This default value precludes valuation of the Voice $_{\mathrm{R}}$ head by matrix Voice, and the rules in (38b) derive the elsewhere spell-out of Voice $e_{\mathrm{R}}$ (which is zero). The embedded $v$-head, on the other hand, realizes whatever features there are in $v$, in this specific case the CAUS feature. And as before, valuation of the $i \varphi$-features of Voice $e_{\mathrm{R}}$ derives the semantic control relation.

(38) a.

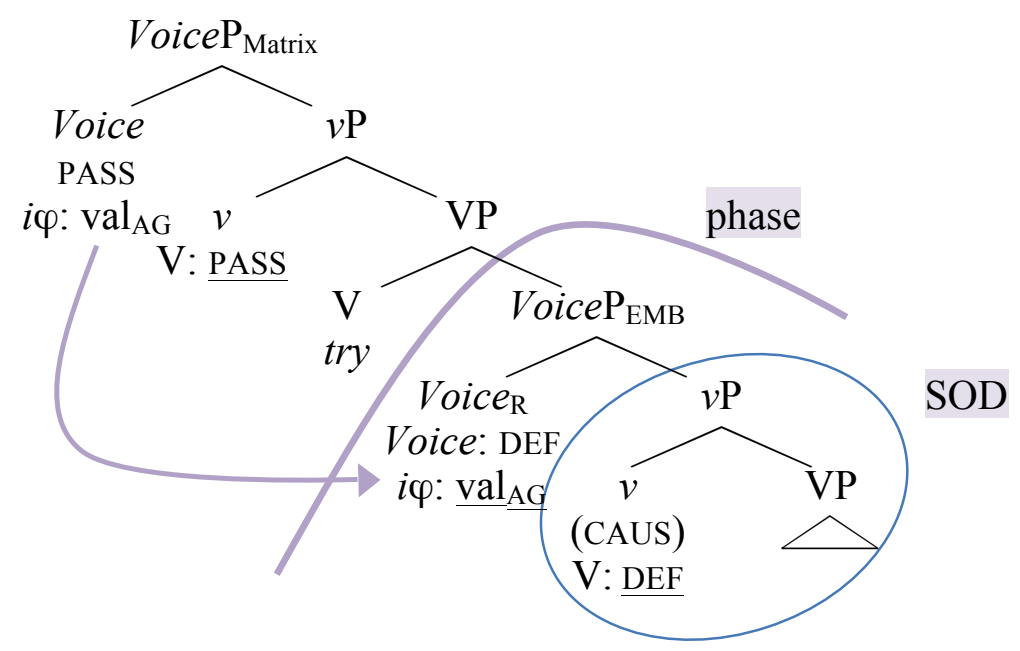

b. Voice.PASS $\rightarrow$ POL

[set of rules for different POL/FAM- $\varphi$ combinations] elsewhere $\rightarrow \varnothing$

c. v.CAUS $\rightarrow \mathrm{peu} / \mathrm{pu}$

elsewhere $\rightarrow \varnothing$

\subsubsection{Japanese}

A very similar analysis applies to Japanese LOM such as (11b), repeated as (39a). The structure is given in (39b) (with a head-initial word order for easier comparison of the structures). As in the other languages, the default value of Voice $_{\mathrm{R}}$ precludes merging an AGENT in the RC. The $i \varphi-$ features of Voice $_{\mathrm{R}}$ are valued by matrix Voice, yielding the semantic sharing of the implicit AGENT. The relevant vocabulary insertion rules are given in (39c). Since Voice $_{\mathrm{R}}$ occurs with a default/dummy Voice value, the insertion of the passive affix is blocked. The rules for $v$.CAUS follow a reviewer suggestion in that the inchoative form is given as the more specific rule and the causative form as the elsewhere case for each verb class (we only give the rules for one class here). The causative form is therefore used in all cases except when $v$ is in the direct context of T/Mod, which is only the case when Voice is not present, e.g., in inchoative contexts such as (9b). ${ }^{18}$

18 Technically, the correct default form would also be derived in (39b) without the presence of an embedded VoiceP. Since RCs lack tense but merge directly with the matrix verb, neither Voice nor $v$ is ever in the local context of T. We maintain the VoiceP structure to derive the control relation. 
(39)

Mado-ga $\quad\left\{\right.$ sim-e $/ *_{\text {sim-ar }} \quad$-tuzuke-rare-tei-ta
window-NOM $\quad$ close-CAUS $/ *^{*}$ close-CAUS.INCH $\}$-continue-PASS-PROG-PAST
'They kept the window closed.'

b. $\quad$ Voice $\mathrm{P}_{\text {Matrix }}$

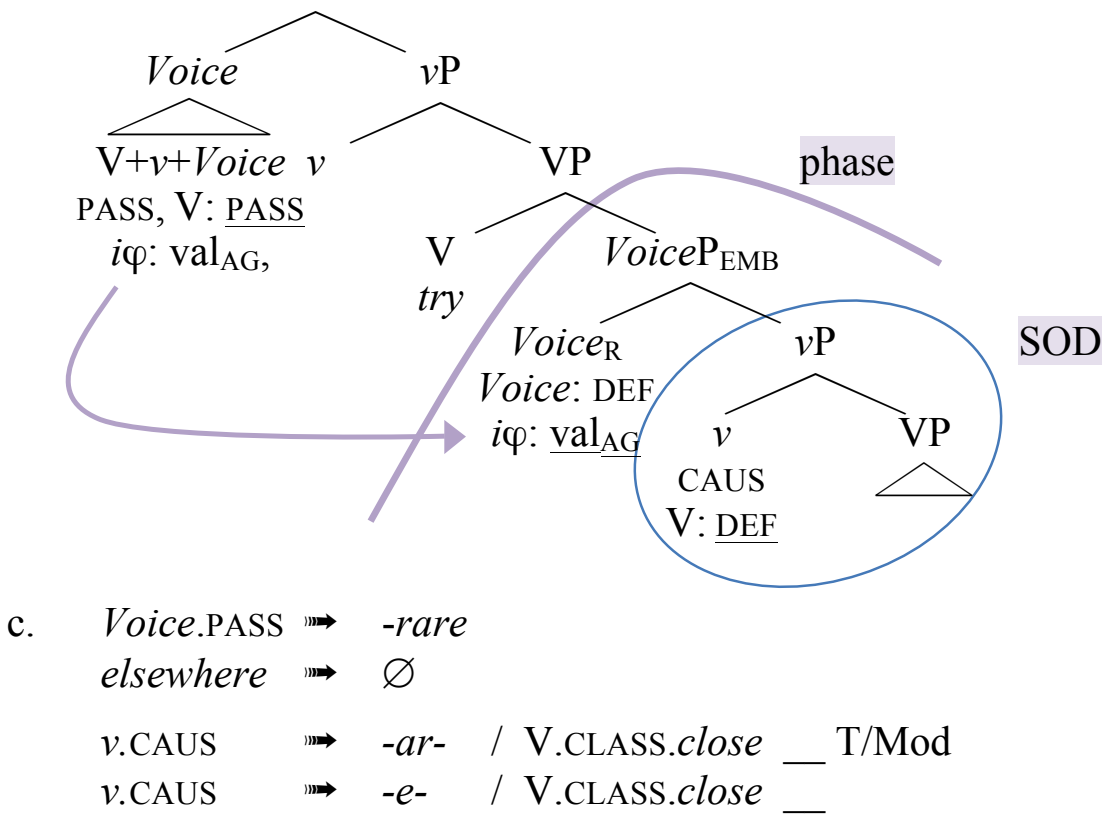

Japanese restructuring illustrates another important aspect of our analysis. As shown in (39), Japanese involves morphological passive, which, in our analysis entails $v(+\mathrm{V})$ incorporation. We have suggested that incorporation is triggered by an EPP-like feature tied to either the Voice head or the PASS value/feature. This assumption correctly predicts that in restructuring contexts, morphological passive languages can involve either voice matching or default voice. In voice matching languages, the trigger for incorporation is tied to the Voice head, hence both passive and restructuring involve incorporation, whereas in default voice languages like Japanese the trigger is only tied to the pass feature (but not the Voice head itself).

\subsubsection{Infinitive default languages}

The last type of default voice language is illustrated in (40). As shown for European Portuguese and Kannada, the embedded verb occurs in the (active) infinitive. This is also the case in German, Italian, and Spanish (see Wurmbrand 2014c). ${ }^{19}$
As casas foram acabadas de construir em 1950
the houses were finished to build in 1950
'They finished to build the houses in 1950' [SW]

European Portuguese

'They finished to build the houses in 1950' [SW]

[Cinque 2002: 5, (7a)]
b. hosa $\operatorname{man}(y) u-\varnothing$ (jaanan-inda)
kaTT-al(u) build-INF
shurumaaD-alpaTT-itu
Kannada new house-NOM (John-by)
started-PASS-3.SG.N

Lit: 'A house was started to be built by John' [Agbayani and Shekar 2007: 10, (1b)]

\footnotetext{
19 As pointed out by Marcel Pitteroff, verbalizations with -ify (which are possible in RCs) may provide evidence for a $v$-head in German RCs, if -ify is located in $v$.
} 
The structure of the RC is as in (38)/(39). The difference lies in the morphological realization rules, which involve an infinitive as the default/elswhere case in these languages. Note that Kannada, like Japanese, is a morphological passive language but a default voice restructuring language, which shows again that incorporation is not necessarily a property of Voice in general.

\subsection{Norwegian and the double passive dilemma}

In section 3.1, we began our journey through the voice domain by noting that Norwegian allows both morphological and periphrastic passive. Interestingly, Norwegian also allows LOM in restructuring contexts, and, as illustrated in (41), allows both voice matching and default voice constructions (Lødrup 2014 notes that speakers may have a preference for voice matching, but both constructions are attested). Since Norwegian is, in our sense, an optional incorporation language, this is exactly what we expect: when it comes to restructuring Voice, both strategies are available. If the default voice strategy is chosen as in (41a), the structure is exactly like the structure proposed for Japanese in (39b). If the voice matching strategy is chosen as in (41b), the structure is like the structure proposed for Chamorro and Isbukun Bunun in (26).
Slike ting forsøkes ofte giøre such things try.PRES.PASS often do.INF 'One often tries to do such things.'
b. Slike ting forsøkes ofte ågjøres such things try.PRES.PASS often to do.INF.PASS 'One often tries to do such things.'

[Lødrup 2014: 371, (13)]

[Ibid: $371,(13)]$

Since Norwegian has both morphological and periphrastic passive, it allows us to see what happens when the two types of passive are combined in voice matching restructuring constructions. As shown in (42), although all four possible combinations are attested by corpus data, the frequency shows a very strong trend: the by far most frequent option is to use morphological passive in the embedded predicate (i.e., $(42 \mathrm{a}, \mathrm{b})$ ). Using embedded periphrastic passive is highly marked, possibly impossible.
(42) a. morphological passive + morphological passive: 73
b. periphrastic passive + morphological passive: 19
c. morphological passive + periphrastic passive: 9
d. periphrastic passive + periphrastic passive: 1

\# of examples in corpus

[Lødrup 2014: 376]

The preference for embedded morphological passive follows from our account. To derive voice matching, incorporation must take place (otherwise the derivation either crashes or default voice must be used). On the other hand, to derive periphrastic passive, we have proposed that no incorporation takes place, which has the effect that Voice is spelled out in a different SOD from $v+\mathrm{V}$, reflecting the morphological independence between the voice auxiliary (Voice) and the verb $(v+\mathrm{V})$. Thus voice matching and periphrastic passive are predicted to be in complementary distribution.

At this point, the question is essentially whether double passives involving a periphrastic embedded passive should be considered to be possible or impossible. If the latter, nothing further needs to be said. On the other hand, if the 10 occurrences in $(42 \mathrm{c}, \mathrm{d})$ reflect that these constructions are in principle possible, however marked, the question arising is how they are 
derived. Following a reviewer suggestion, a way to account for such cases, including their marked status would be to assume that incorporation takes place in the RC, leading to voice matching, however, that for some speakers a marked post-syntactic fission rules applies which again separates the Voice head from $v+\mathrm{V}$. This would allow Voice to be spelled out as an independent auxiliary while at the same time matching with the matrix Voice. Such rule is arguably marked and thus captures the dispreference noted in Lødrup (2014) for such constructions. ${ }^{20}$

A similar issue may arise for English, which is typically analyzed as not allowing voice restructuring since LOM of the form *The car was tried to repair is entirely impossible. However, double passives are found (J. Merchant, p.c.). Like in Norwegian, the empirical situation is peculiarly unclear: while English double passives are fairly frequent in corpora (see (43) for some examples), native speakers are rather uneasy and undecided about the grammaticality of these examples. A similar uneasiness has been noted for Norwegian by Lødrup (2014: 370): "Voice agreeing long passives can have an air of informal or even substandard language, and they are sometimes frowned upon by informants. However, examples abound in web texts, and they can be found in typical written genres, even in documents from the government." For English, on the other hand, some speakers have described these examples as 'overdone formal speech', and the same impression has been reported to us for Brazilian Portuguese (R. Lacerda, p.c.). ${ }^{21}$

(43) a. And how much fuel is proposed to be produced?

b. That's how our politics has been taught to be played.

[June 2, 2008, NPR; J. Merchant, p.c.]

c. Snapshots will be tried to be updated on reboot/shutdown

[speech 4/17/08 by Obama; J. Merchant, p.c.)]

[http://manpages.ubuntu.com/manpages/hardy/man7/casper.7.html]

d. Chapter 2 will be begun to be written sometime this weekend...

[https://www.facebook.com/pages/Heroes-Jason-Storme-books/359571210721163]

e. The budget for next year will be begun to be prepared next month by the finance committee.

[http://quake.stanford.edu/ todd/pacrc-cnotes/cn0002]

f.. $\quad$ and Jerusalem will be begun to be rebuilt

g. $\quad$ another House of the Lord will be begun to be erected

[via Google books]

[via Google books]

20 We thank the reviewer for this constructive suggestion.

${ }^{21}$ See also George and Kornfilt (1977), Kornfilt (1996) for double passive in Turkish and Wurmbrand (2014c) for further languages allowing double passives. In Japanese, double passive is marginally possible with aspectual matrix verbs as in (i), but impossible with lexical restructuring verbs such as wasure 'forget' in (ii). We currently do not have any further insights why different restructuring verbs behave differently regarding double passive.
i. ?1950-nen-goro hambaagaa-ga nihon-de tabe-rare-hajime-rare-ta
'They began to eat hamburgers around 1950.'
ii. *Kono ronbun-ga yom-are-wasure-rare-ra this paper-NOM read-PASS-forget-PASS-PAST Intended. 'They forgot to read this paper.' 
Although the exact status of double passive constructions cannot be determined at this point, the cross-linguistic difficulty can be taken to indicate that this option should be considered as marked, at best. We therefore leave the empirical issue open, but only note that in our system, double (periphrastic) passives are not expected, except via a (brute-force) fission rule.

\section{Conclusion}

This paper has offered a feature system for the voice domain, as well as morphological spell-out rules for passive and restructuring in a range of languages. Several narrow and broad conclusions regarding the organization and architecture of the voice domain have been reached. Among others, we have shown that a split voice domain is supported (directly or indirectly) by the morphological (combination of affixes), semantic (agent interpretation), and syntactic (agreement and domain effects) properties of passive and restructuring. Furthermore, cross-linguistic morphological differences in the realization of voice properties have been attributed to a cyclic spell-out approach in which vocabulary insertion applies incrementally. We have further argued that the morphological properties including agreement are straightforwardly accounted for in an approach where the phasal projection of the voice domain is the top projection of the entire voice domain, whichever projection that is, and where the voice domain always constitutes a phase, even in passive contexts. Lastly, the paper has offered a detailed account of several properties of voice restructuring, such as the distribution of voice marking, agreement, and the inchoativecausative alternation, including cross-linguistic variation found in these properties. The main conclusion reached was that restructuring clearly involves a voice domain, but that this domain is deficiently equipped with features values, which requires establishing a dependency with the matrix voice domain. The account has been couched in a valuation-based Reverse Agree framework and a uniform feature system has been proposed which derives the attested properties and variation.

\section{References}

Agbayani, Brian, and Chandra Shekar. 2007. Restructuring and clausal architecture in Kannada. In Phrasal and clausal architecture, ed. Simin Karimi, Vida Samiian and Wendy Wilkins, 8-24. Amsterdam/Philadelphia: Benjamins.

Alexiadou, Artemis, Elena Anagnostopoulou, and Florian Schäfer. 2006. The properties of anticausatives cross-linguistically. In Phases of interpretation, ed. Mara Frascarelli, 187211. Berlin: Mouton de Gruyter.

Alexiadou, Artemis, Elena Anagnostopoulou, and Susi Wurmbrand. 2014. Movement vs. long distance Agree in raising: Disappearing phases and feature valuation. In Proceedings of the North Eastern Linguistics Society Annual Meeting 43, eds. Hsin-Lun Huang, Ethan Poole and Amanda Rysling, 1-12. Amherst: University of Massachusetts, GLSA.

Arregi, Karlos, and Andrew Nevins. 2012. Morphotactics: Basque auxiliaries and the structure of spellout. Dordrecht: Springer.

Béjar, Susana, and Milan Rezac. 2009. Cyclic agree. Linguistic Inquiry 40.1:35-73.

Bobaljik, Jonathan D. 2012. Universals in comparative morphology: Suppletion, superlatives, and the structure of words. Cambridge: MIT Press.

Bondaruk, Anna. 2004. PRO and control in English, Irish and Polish: A Minimalist analysis. Lublin: Wydawnictwo KUL. 
Bowers, John. 2002. Transitivity. Linguistic Inquiry 33.2:183-224.

Chen, Tingchun. 2010. Restructuring in Mayrinax Atayal. B. Arts Honours Thesis. Montréal: McGill University.

Chung, Sandra. 1998. The design of agreement: evidence from Chamorro. Chicago: University of Chicago Press.

Chung, Sandra. 2004. Restructuring and verb-initial order in Chamorro. Syntax 7.3:199-233.

Cinque, Guglielmo. 2002. The interaction of passive, causative, and 'restructuring' in Romance. In The syntax of Italian dialects, ed. Christina M. Tortora, 50-66. Oxford: Oxford University Press.

Collins, Chris. 1997. Local Economy. Cambridge: MIT Press.

Folli, Raffaella, and Heidi Harley. 2005. Flavours of v: consuming results in Italian and English. In Aspectual inquiries, eds. Paula Kempchinsky and Roumyana Slabakova, 95-120. Dordrecht: Springer.

Fukuda, Shin. 2007. On the control/raising ambiguity with aspectual verbs: a structural account. In Studies in Complement Control 47, ed. Barbara Stiebels, 159-195. ZAS Papers in Linguistics.

George, Leland, and Jacqueline Kornfilt. 1977. Infinitival double passives in Turkish. In Proceedings of the North Eastern Linguistics Society Annual Meeting 7, eds. Judy Kegl, David Nash and Anne Zaenen. Amherst: GLSA.

Harley, Heidi. 2009. The morphology of nominalizations and the syntax of vP. In Quantification, definiteness and nominalization, eds. Anastasia Giannakidou and Monika Rathert, 320342. Oxford: Oxford University Press.

Harley, Heidi. 2013. The 'bundling' hypothesis and the disparate functions of little v. Talk given at the Little $v$ workshop, Leiden.

Jacobsen, Wesley. 1992. The transitive structure of events in Japanese Tokyo: Kuroshio.

Kageyama, Taro. 1996. Dooshi imi ron [Theory of verbal semantics]. Tokyo: Kuroshio.

Kornfilt, Jaklin. 1996. NP-movement and 'restructuring'. In Current issues in comparative grammar, ed. Robert Freidin, 121-147. Dordrecht: Kluwer.

Kratzer, Angelika. 1996. Severing the external argument from its verb. In Phrase structure and the lexicon, eds. Johan Rooryck and Laurie Zaring, 109-137. Dordrecht: Kluwer.

Legate, Julie Anne. 2003. Some Interface Properties of the Phase. Linguistic Inquiry 34.3:506516.

Legate, Julie Anne. 2010a. Not-so-implicit agents. Talk given at the 17th Meeting of the Austronesian Formal Linguistics Association, Stony Brook University.

Legate, Julie Anne. 2010b. The structure of agents in implicit passives. Talk given at the 41st annual meeting of the North East Linguistics Society, Philadelphia.

Legate, Julie Anne. 2012. Subjects in Acehnese and the nature of the passive. Language 88.3:495-525.

Legate, Julie Anne. 2014. Voice and v: Lessons from Acehnese. Cambridge: MIT Press.

Lødrup, Helge. 2014. Long passives in Norwegian: Evidence for complex predicates. Nordic Journal of Linguistics 37.3:367-391.

Marantz, Alec. 2008. Phases and words. In Phases in the theory of grammar, eds. Sook-Hee Choe, Yang-Soon Kim, Sung-Hun Kim and Alec Marantz, 191-220. Seoul: Dong In Publisher. 
Pesetsky, David, and Esther Torrego. 2007. The syntax of valuation and the interpretability of features. In Phrasal and clausal architecture, eds. Simin Karimi, Vida Samiian and Wendy Wilkins, 262-294. Amsterdam: Benjamins.

Pitteroff, Marcel. 2014. Non-canonical lassen middles. Doctoral dissertation, University of Stuttgart.

Pitteroff, Marcel, and Artemis Alexiadou. 2012. On the Properties of German sich-lassen Middles. In Coyote Working Papers: Proceedings of the 29th West Coast Conference on Formal Linguistics, eds. Jaehoon Choi et al., 214-222. University of Arizona: Tucson.

Pylkkänen, Liina. 2008. Introducing arguments. Cambridge: MIT Press.

Pylkkännen, Liina. 2002. Introducing arguments. Doctoral dissertation, MIT, Cambridge.

Sauerland, Uli. 2003. Intermediate adjunction with A-movement. Linguistic Inquiry 34.2:308314.

Schäfer, Florian. 2008. The syntax of (anti-)causatives: External arguments in change-of-state contexts. Amsterdam: Benjamins.

Shih, Chao-Kai. 2014. On restructuring in Takibakha Bunun. Ms., National Tsing Hua University. Taiwan.

Shimamura, Koji, and Susi Wurmbrand. 2014. Two types of restructuring in JapaneseEvidence from scope and binding. In 7th Formal Approaches to Japanese Linguistics, eds. Shigeto Kawahara and Mika Igarashi, 203-214: MIT Working Papers in Linguistics.

Thornton, Abigail. 2015. If verbal number is lo-low. Ms., University of Connecticut. Storrs.

Volpe, Mark. 2005. Japanese Morphology and its theoretical consequences: Derivational morphology in Distributed Morphology. Doctoral dissertation, Stony Brook University.

Wu, Hsiao-hung Iris. 2013. Restructuring and Clause Structure in Isbukun Bunun. Oceanic Linguistics 52.1:36-52.

Wurmbrand, Susi. 2001. Infinitives: Restructuring and clause structure. Berlin/New York: Mouton de Gruyter.

Wurmbrand, Susi. 2012. The syntax of valuation in auxiliary-participle constructions. In Coyote Working Papers: Proceedings of the 29th West Coast Conference on Formal Linguistics, eds. Jaehoon Choi et al. University of Arizona: Tucson.

Wurmbrand, Susi. 2013a. Complex predicate formation via voice incorporation. Ms., University of Connecticut. Storrs.

Wurmbrand, Susi. 2013b. Tagalog infinitives: Consequences for the theory of phases, voice marking and extraction. Ms. Storrs.

Wurmbrand, Susi. 2014a. The Merge Condition: A syntactic approach to selection. In Minimalism and Beyond: Radicalizing the interfaces, eds. Peter Kosta, Lilia Schürcks, Steven Franks and Teodora Radev-Bork, 139-177. Amsterdam: Benjamins.

Wurmbrand, Susi. 2014b. Restructuring across the world. In Complex Visibles Out There. Proceedings of the Olomouc Linguistics Colloquium 2014, eds. Ludmila Veselovská and Markéta Janebová, 275-294. Olomouc: Palacký University.

Wurmbrand, Susi. 2014c. Restructuring across the world-Data summary.

Wurmbrand, Susi, and Youssef Haddad. To appear. Cyclic Spell-Out Derived Agreement in Arabic Raising Constructions. In Perspectives on Arabic Linguistics XXVIII., eds. Youssef Haddad and Eric Potsdam. Amsterdam: Benjamins.

Susi Wurmbrand

susanne.wurmbrand@uconn.edu
Koji Shimamura

koji.shimamura@uconn.edu 